\title{
Spectrophotometric Studies on the Reaction of Diaveridine with Some Sulfonphthalein Dyes Based on Ion-Pair/Ion-Associate Complexes Formation
}

\author{
A. L. El-Ansary, ${ }^{1}$ N. S. Abdel-Kader ${ }^{(D},{ }^{1}$ and A. M. Asran ${ }^{2}$ \\ ${ }^{1}$ Department of Chemistry, Faculty of Science, University of Cairo, Giza, Egypt \\ ${ }^{2}$ Modern Academy In Maadi For Engineering and Technology, Cairo, Egypt \\ Correspondence should be addressed to N. S. Abdel-Kader; norabdelkader@sci.cu.edu.eg
}

Received 31 January 2018; Revised 10 September 2018; Accepted 13 September 2018; Published 5 November 2018

Academic Editor: Maria Carmen Yebra-Biurrun

Copyright (c) 2018 A. L. El-Ansary et al. This is an open access article distributed under the Creative Commons Attribution License, which permits unrestricted use, distribution, and reproduction in any medium, provided the original work is properly cited.

\begin{abstract}
The ion-associate complexes of diaveridine were prepared in a solution and studied spectrophotometrically. The bulky counter anions such as sulfonphthalein acidic dyes, namely, bromocresol green (I), bromophenol blue (II), bromothymol blue (III), bromocresol purple (IV), bromocresol blue (V), o-cresol red (VI), p-cresol blue (VII), and m-cresol purple (VIII) were used for ion-associate complexes formation. The optimal characteristics for the color formation and the stoichiometry of the reaction were evaluated. Spectral characteristics and stability constants of the formed ion associates are discussed in terms of nature of donor and acceptor molecular structures. The molar absorptivities and association constants for the colored complexes were evaluated using the Benesi-Hildbrand equation. Conformity to Beer's law enabled the assay of dosage form of the drug. The molar absorptivity, specific absorptivity, Sandell sensitivity, correlation coefficient, and detection and quantification limits were also calculated. The methods were validated in terms of accuracy, specificity, precision, and linearity. Also, spectrophotometric determination of the drug in pure and pharmaceutical preparations was tested.
\end{abstract}

\section{Introduction}

Compounds containing pyrimidine rings play a significant role in many biological systems due to their coordinating properties. So, substituted 2,4 diaminopyrimidines are widely employed as metabolic inhibitors of pathways leading to the synthesis of proteins and nucleic acids [1]. Among these kinds of compounds, diaveridine (5-[(3,4-diethoxyphenyl)methyl]pyrimidine-2,4-diamine) is a well known biological agent, and also, it can be used as an antiprotozoal agent in animals $[2,3]$. Diaveridine was found to act as a strong antibacterial drug due in part to two methoxy groups substituted on the benzene rings [4], in addition to the presence of two aromatic amino groups or the acidic hydrogen in the molecules make it acts as a strong acceptor $[5,6]$. It has wide antibacterial activity against many Gram-negative and Gram-positive bacteria [7]. It also has remarkable activity against coccidian so; it is used in the treatment of chicken coccidiosis, fowl cholera, and pullorum [8]. Little work has been observed on this drug. Subsequently, we aim to study the reaction of this drug with bulky counter anions such as sulfonphthalein acidic dyes. Sulfonphthaleins are one of the most interesting families of anionic dyes and have attracted scientific attention; this is attributed to their molecular structure which allows formation of ion-associate complexes with various drugs, where ion pair or ion association complexes are those complexes in which the analytical species associates with oppositely charged ions to form neutral compounds [9-12]. Ion pair complexes formation methods were used for the visible spectrophotometric determination of various drugs in the literature through their ion pairing with oppositely charged dyes to form colored complexes [13].

The proposed method was applied to the analysis of the bulk drug and its dosage form. The results of the analysis 
were validated statistically and recovery ranges were calculated. The results were compared with those of an official method. In the proposed method, no extraction step was utilized thus reducing the time and error involved in the estimation.

\section{Experimental}

2.1. Materials and Reagents. All chemicals used in this investigation were chemically pure grade ( $\mathrm{BDH}$ or Aldrich). They included bromocresol green, bromophenol blue, bromothymol blue, bromocresol purple, bromocresol blue, cresol red, cresol blue, cresol purple (BDH Chemicals Ltd., Poole, England); Diaverdine (Elnaser pharmaceutical chemicals Cairo, Egypt); and New-Cox powerful anticoccidial watersoluble powder (Atco Pharma for Pharmaceutical Industry, Cairo, Egypt). The solvents used in this study chloroform, dichloromethane, dichloroethane, methanol, ethanol, acetone, acetonitrile, dioxane, dimethyl formamide, and dimethyl sulphoxide were further purified using standard methods [14]. All chemicals, solvents, and reagents were of analytical grade, and their solutions were prepared and diluted in highly purified solvents.

Diaverdine was used to prepare the stock solution $1.0 \times 10^{-3} \mathrm{~mol} / \mathrm{L}$, by dissolving an appropriate amount $(0.0260 \mathrm{~g})$ of the drug in $1 \mathrm{~mL}$ of absolute ethanol and then diluted to $100 \mathrm{~mL}$ with chloroform. The dyestuff was used as $1.0 \times 10^{-3} \mathrm{~mol} / \mathrm{L}$, prepared by dissolving the accurately weighed amounts in the least amount of absolute ethanol and then completed to the final volume with chloroform.

2.2. Instrumentations. Absorbance measurements were made on Shimadzu 1601PC, UV-visible spectrophotometer (Shimadzu, Tokyo, Japan) and PYE-UNICAM SP 1750 UVvisible recording spectrometer using matched cells of $1 \mathrm{~cm}$ path length.

A techne circulator thermost Model C-100 (Cambridge, England) was used to control the temperature of the test solution.

2.3. Preparation of Ion-Associate Complexes. The solutions of ion-associate complexes were prepared by adding $1 \mathrm{~mL}$ of standard solution $1.0 \times 10^{-3} \mathrm{~mol} / \mathrm{L}$ of the drug to a series of $10 \mathrm{~mL}$ calibrated flasks followed by $2.0 \mathrm{~mL}$ of $1.0 \times 10^{-3} \mathrm{~mol} / \mathrm{L}$ sulfonphthalein dye solution. The mixture is then completed to the mark with chloroform. For safety, all operations involving handling chloroform must be conducted in a properly operating chemical fume hood to minimize over exposure and widespread contamination throughout the laboratory and minimize all chloroform contact with gloved hands.

2.4. Determination of the Drug in Pharmaceutical Preparation. The analysis of diaveridine in New-Cox is performed by weighting $(0.0573 \mathrm{~g}) \mathrm{New}-\mathrm{Cox}$ drug corresponding to $1.0 \times 10^{-3} \mathrm{~mol} / \mathrm{L}$, then dissolving it in $1 \mathrm{~mL}$ of absolute ethanol, after that diluting it to $100 \mathrm{~mL}$ with the suitable solvent. Different aliquots of this solution were subjected to analysis as reported.

\section{Results and Discussion}

The importance of drug complexes stems from the fact that when a drug becomes a part of an ion-associate complex, it acquires new properties which may be completely different from those of the original drug.

Sulfonphthaleins (Scheme 1) are anionic dyes; their structure has two tautomers present in equilibrium. But due to strong acidic nature of the sulphonic acid group, the lactoid ring is opened and quinoid from must be predominate [15].

Sulfonphthalein dyes have in their general molecular structure, shown in Scheme 1, different substituents so they may affect the dissociation of the reagent and the formation of the ion-associate complexes. The presence of the electron attracting groups in sulfonphthalein skeleton such as bromine atom increase the value of $K_{\mathrm{a}}$ of the acidic dye, which makes it even more electronegative, and due to the inductive effect, it will extract electrons, thus diminishing the carbon $\alpha$ electron density inducing a positive inductive effect and a structure having a relatively high energy that will be destabilizing the acidic dye with respect to the anionic form (conjugate base); as the presence of bromine is electron attracting, this will disperse the charge and stabilize the anionic form, thus producing a stronger acidic dye, and consequently the dissociation will be larger. Accordingly, the dyes I, II, and V contain four bromine atoms or III and IV which have two bromine atoms will give the more stable anionic form.

When substituents such as methyl or isopropyl which are electron-donors are incorporated, there would be an inductive effect occurring in the molecule, namely, elevating the charge density that will in turn destabilize the anionic form, and thus the acid will "prefer" not to dissociate. Therefore, the $K_{\mathrm{a}}$ will be smaller, making the acidic dye a weak one. It occurs in VI, VII, and VIII dyes.

Many amines easily form complexes with these dyestuff. Chloroform is the best solvent to achieve the highest absorbance value. The sequence reagent-drug-solvent is the best one for the formation of the complexes in all cases. When a solution of dyestuff in chloroform is added in a large excess to the drug solution, an intense color is immediately produced. This is due to the conversion of the dye into an open quinonoidal anionic derivative, which forms an ionassociate with the drug. So, the color of dyestuff is due to the opening of lactoid ring and subsequent formation of the quinoid group as represented in Scheme 2, and anionic dyes of the sulfonphthalein group present mainly in anionic form; this facilitates the formation of ion-associates complexes. The possible reaction mechanisms are given in Scheme 3.

The parameters that affect the formation of ion-associate complexes such as selection of suitable wavelength, effect of reagent concentration, effect of sequence of addition, effect of solvents, effect of time, effect of temperature, and effect of interference were studied. 


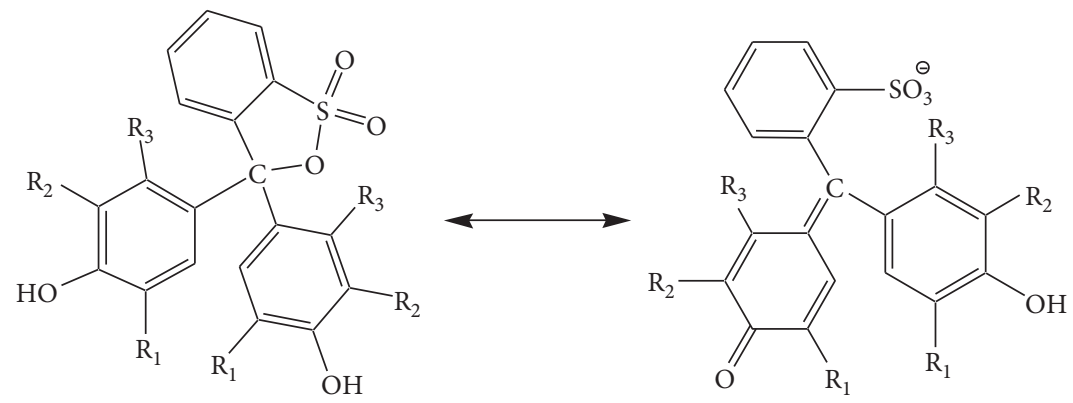

Lactoid ring of sulfonphthalein (R)

Quinoid ring of sulfonphthalein $\left(\mathrm{R}^{-}\right)$

\begin{tabular}{lcccc}
\hline Number & $\begin{array}{c}\text { The name of } \\
\text { reagent }\end{array}$ & $\mathrm{R}_{1}$ & $\mathrm{R}_{2}$ & $\mathrm{R}_{3}$ \\
\hline I & Bromocresol green & $\mathrm{Br}$ & $\mathrm{Br}$ & $\mathrm{CH}_{3}$ \\
II & Bromophenol blue & $\mathrm{H}$ & $\mathrm{Br}$ & $\mathrm{Br}$ \\
III & Bromothymol blue & $\mathrm{Br}$ & $\left.\mathrm{CH}_{(\mathrm{CH}}\right)$ & $\mathrm{CH}_{3}$ \\
IV & Bromocresol purple & $\mathrm{Br}$ & $\mathrm{CH}_{3}$ & $\mathrm{H}$ \\
V & Bromocresol blue & $\mathrm{Br}$ & $\mathrm{CH}_{3}$ & $\mathrm{Br}$ \\
VI & $o$-Cresol red & $\mathrm{CH}_{3}$ & $\mathrm{H}$ & $\mathrm{H}$ \\
VII & $p$-Cresol blue & $\mathrm{H}$ & $\mathrm{CH}_{3}$ & $\mathrm{H}$ \\
VIII & $m$-Cresol purple & $\mathrm{H}$ & $\mathrm{H}$ & $\mathrm{CH}_{3}$ \\
\hline
\end{tabular}

Scheme 1: The different forms of sulfonphthalein dyes.<smiles>COc1cc(Cc2cc(OC)cc(OC)c2)cc(Cc2cc(N)nc(N)n2)c1</smiles>

Scheme 2: Positively charged protonated forms of diaveridine.

The formed ion-associate complexes were formed instantaneously and remain stable for more than 48 hours. This means that the formed complexes are quite stable.

The absorption spectra were recorded for the formed complexes in the visible region at a range $400-550 \mathrm{~nm}$. The wavelength corresponding to the maximum absorption for each ion-associate is determined and listed in Table 1.

On studying the effect of the various organic solvents chloroform, dichloromethane, dichloroethane, methanol, ethanol, acetone, acetonitrile, dioxane, dimethyl formamide, and dimethyl sulphoxide on the absorbance of the investigated ion-associates, it was found that chloroform was the best solvent to achieve the highest absorbance value.

The effect of time on the formation and stability of the complexes was studied by measuring the absorbance of the complexes at increasing time intervals (from 5 minutes to 48 hours). The results showed that the formed ion-associate complexes are formed instantaneously and remain stable for more than 48 hours. This means that the formed complexes are quite stable.

Also, the effect of temperature on the formation and the stability of the complexes were studied by measuring the 


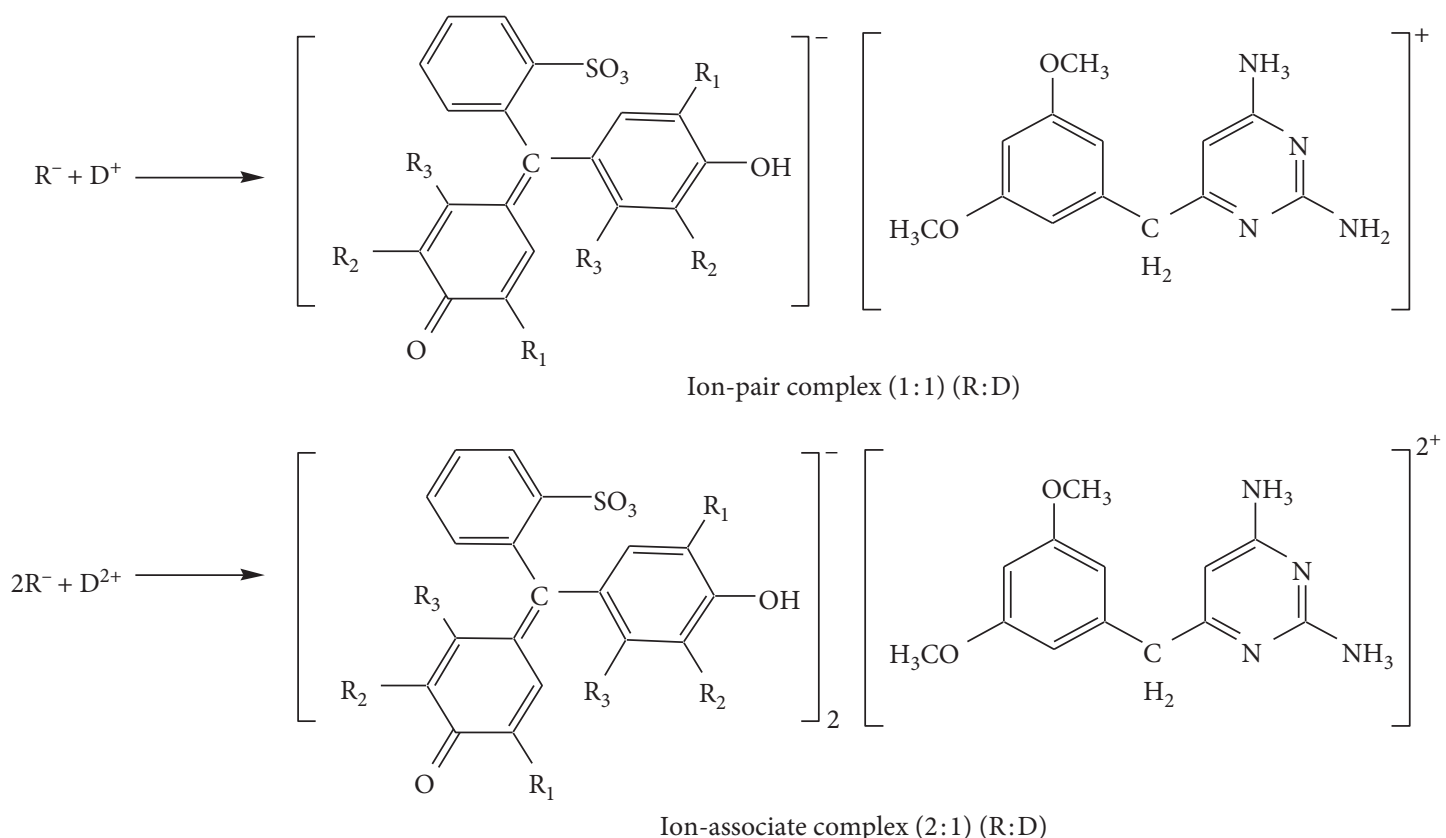

Scheme 3: The reaction mechanisms of the formation of ion-pair and ion-associate complexes.

TABLE 1: Spectral characteristics of the calibration graphs and analytical data in the determination of the studied dug using the ion-associate complex formation method.

\begin{tabular}{|c|c|c|c|c|c|c|c|c|c|c|c|c|c|}
\hline \multirow[t]{2}{*}{ Ion-pair } & \multirow{2}{*}{$\lambda_{\max }$} & \multirow{2}{*}{$\begin{array}{c}\text { Beer's low } \\
\text { up to } \mu \mathrm{g} \\
\mathrm{mL}^{-1}\end{array}$} & \multirow{2}{*}{$\begin{array}{l}\text { Ringbom } \\
\text { range } \\
\left(\mu \mathrm{g} \mathrm{mL}^{-1}\right)\end{array}$} & \multirow{2}{*}{$\begin{array}{c}\mathrm{DL}^{\mathrm{a}} \\
\left(\mu \mathrm{g} \mathrm{mL}^{-1}\right)\end{array}$} & \multirow{2}{*}{$\begin{array}{c}\mathrm{QL}^{\mathrm{b}} \\
\left(\mu \mathrm{g} \mathrm{mL}^{-1}\right)\end{array}$} & \multirow[t]{2}{*}{$\varepsilon^{c}$} & \multirow{2}{*}{$\begin{array}{c}\mathrm{SS}^{\mathrm{d}} \\
\left(\mu \mathrm{g} \mathrm{cm}^{-2}\right)\end{array}$} & \multicolumn{3}{|c|}{$\begin{array}{l}\text { Quantitative } \\
\text { parameter }^{\mathrm{e}}\end{array}$} & \multirow{2}{*}{$\begin{array}{c}\text { Error } \\
(\%)\end{array}$} & \multirow{2}{*}{$\begin{array}{l}\text { RSD } \\
(\%)\end{array}$} & \multirow{2}{*}{$\begin{array}{c}95 \% \\
\text { confidence }\end{array}$} \\
\hline & & & & & & & & $a$ & $b$ & $R$ & & & \\
\hline -I & 420 & 6.89 & 2.95-119 & 0 & 2.50 & 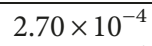 & 0.0096 & 0.014 & 0.018 & 0.9967 & 0.19 & 0.21 & 0.2 \\
\hline D-II & 44 & & 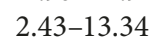 & & & & & .069 & 0.043 & & 0.38 & 023 & \\
\hline D-III & 430 & & & & & & 0.0 & 072 & 0.034 & 0.9 & 0.10 & 0.15 & \\
\hline D-IV & 415 & 20 & $2.95-$ & 0.62 & 2.07 & $23 x$ & 0.0119 & 0.084 & 0.030 & 0.9972 & 0.48 & 0.15 & 0.2645 \\
\hline $\mathrm{D}-\mathrm{V}$ & 445 & 18.17 & $2.95-12.95$ & 0.85 & 2.48 & $2.16 \times 10^{-4}$ & 0.0120 & 0.083 & 0.063 & 0.9991 & 0.29 & 0.18 & 0.2544 \\
\hline D-VI & 430 & 1801 & $325-156$ & & 63 & $1.74 \times 10^{-4}$ & 0.0149 & 0.066 & 0.013 & 0.9996 & 0.57 & 0.26 & 0.1544 \\
\hline D-VII & 430 & 16.81 & $2.01-1$ & 2.29 & 7.6 & $2.22 \times 10^{-4}$ & 0.0118 & 0.085 & 0.015 & 0.9991 & 0.66 & 0.28 & 0.2618 \\
\hline D-VIII & 440 & 17.98 & $3.87-15.57$ & 2.60 & 8.83 & $1.20 \times 10^{-4}$ & 0.0051 & 0.046 & 0.004 & 0.9997 & 0.76 & 0.32 & 0.2227 \\
\hline
\end{tabular}

${ }^{\mathrm{a}}$ Detection limit. ${ }^{\mathrm{b}}$ Quantification limit. ${ }^{\mathrm{c}}$ Molar absorptivity $\left(\mathrm{L} \mathrm{mol}^{-1} \mathrm{~cm}^{-1}\right)$. ${ }^{\mathrm{d}}$ Sandell sensitivity. ${ }^{\mathrm{e}}$ Regression equation $A=a+\mathrm{bC}$, where $\mathrm{C}$ is the concentration in $\mu \mathrm{g} \cdot \mathrm{mL}^{-1}$.

absorbance of the ion-associates complexes at different temperatures over the range $20^{\circ} \mathrm{C}-35^{\circ} \mathrm{C}$. The results showed that the temperature has no effect on the formation of the ion-associate complexes. From that, we can deduce that the proposed methods are very suitable for routine analysis of the pure drugs and the pharmaceutical preparations, and neither temperature control nor extraction step is required.

The effects of the reagents were studied; it was found that the maximum color intensity of the complexes was achieved with $2.0 \times 10^{-4} \mathrm{~mol} / \mathrm{L}$ of reagent solutions.

The effect of diluents, excipients, and additives which often accompany diaveridine in its dosage form was studied. There is no shift in the absorption maximum $\left(\lambda_{\max }\right.$ of the complexes) due to the presence of excipients. This indicated that there are no possible interferences expected from excipients.
The stoichiometry of the formed complexes was determined by Job's method of continuous variation [16] and molar ratio method (MRM) [17]. The results indicate that $1: 1$ and $1: 2$ (drug:dye) ion-associates were formed (Figures 1 and 2).

3.1. Obeyance to Lambert Beer's Law and Ringbom Optimum Range. To test the obeyance to Lambert Beer's law, the reagent concentration was kept constant at $2.0 \times 10^{-4} \mathrm{~mol} / \mathrm{L}$ while that of the drug was regularly varied from $1.0 \times 10^{-5}$ to $8.0 \times 10^{-5} \mathrm{~mol} / \mathrm{L}$. The absorbances of the resulting solutions were measured at their $\lambda_{\max }$ against a blank solution containing the same amount of the reagent at the same conditions and plotted against concentration. The concentration ranges for determination of the drug and the molar absorptivity values $(\varepsilon)$ are expressed in $\mathrm{L} \cdot \mathrm{mol}^{-1} \cdot \mathrm{cm}^{-1}$ and are 


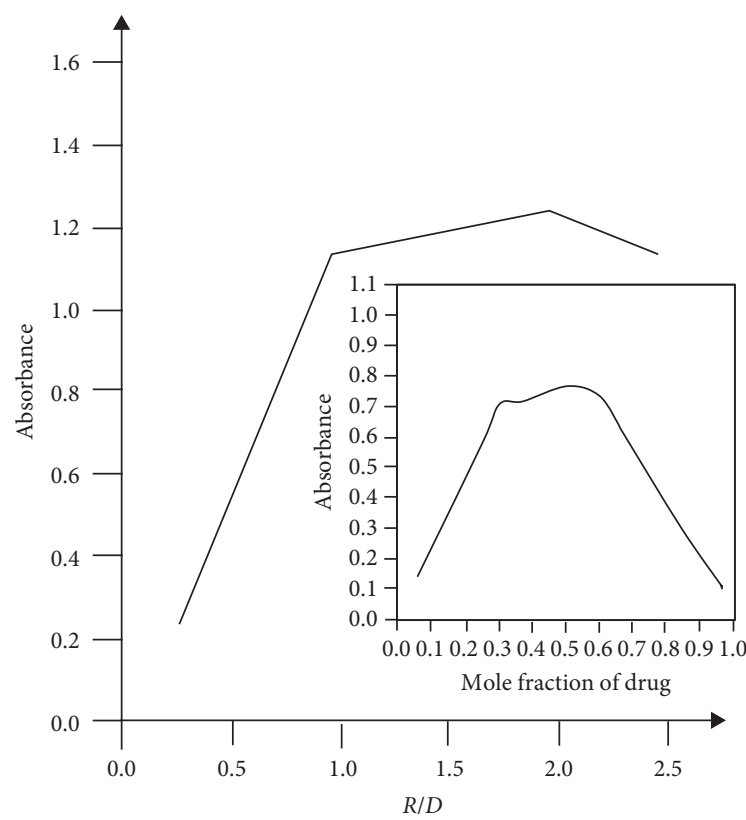

(a)

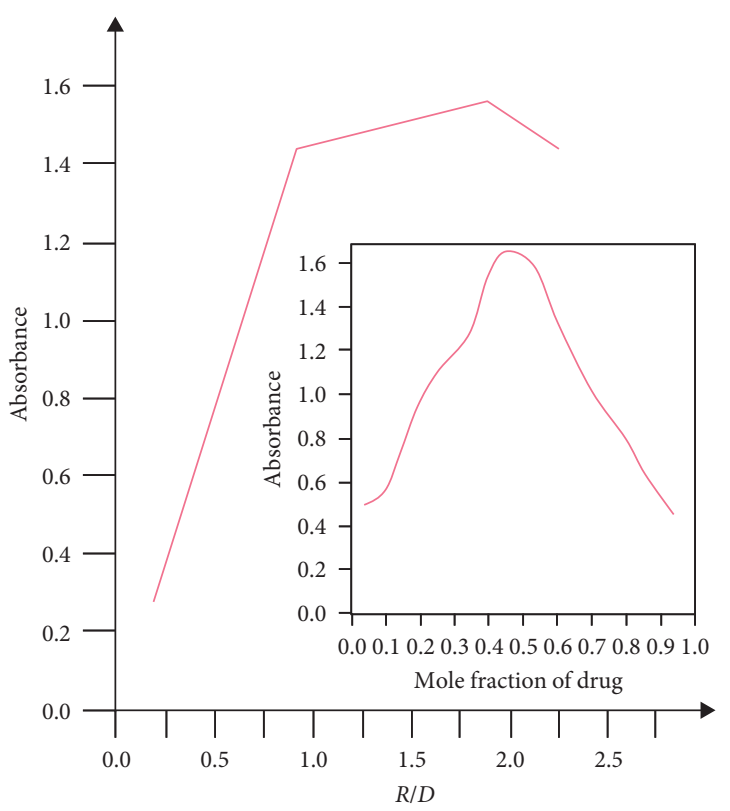

(c)

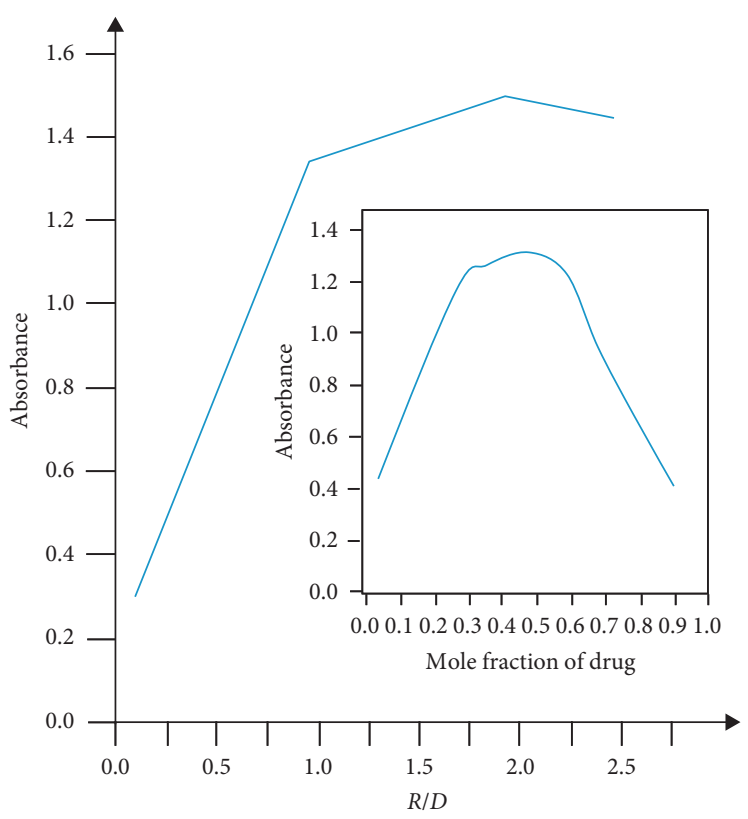

(b)

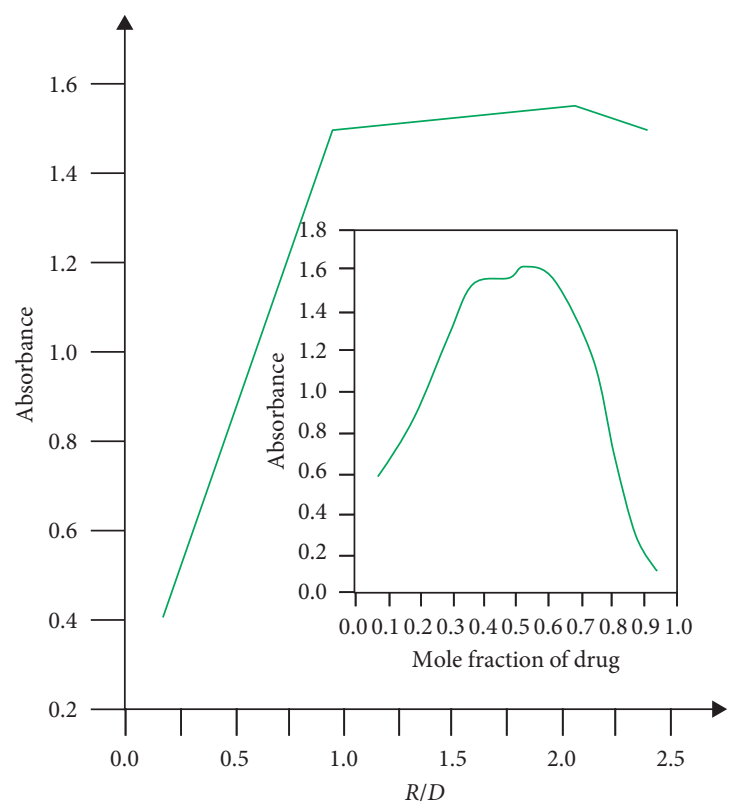

(d)

FIGURE 1: Stoichiometry of formed complexes between diaveridine and reagents I (a), II (b), III (c), and IV (d) complexes by MRM and CVM method.

shown in Table 1. The values of the molar absorptivities indicate high sensitivity of the method. Also, Ringbom [18] plots were drawn (Figure 3). The results are also located in Table 1.

\subsection{Validation of the Analytical Procedures for Determination} of Diaveridine. Validation of analytical procedures is the process of determining the suitability of a given methodology for providing useful analytical data. Validation of the method is performed for identification of the sources of potential errors and quantification of the potential errors in the method [19].
The linearity of a method was examined by measuring the absorbance as a function of concentration of the drug under the optimized conditions. Applying the least squares method to absorbance-concentration data, it was found that the lines almost pass in the vicinity of the origin. The correlations coefficients are very close to unity and indicate good linearity. It is more convenient to express and compare the sensitivities of spectrophotometric methods in terms of specific absorptivity $(a)\left(\mathrm{L} \cdot \mathrm{g}^{-1} \cdot \mathrm{cm}^{-1}\right)$ [20] corresponding to the absorbance of $1 \mu \mathrm{g} / \mathrm{mL}$ in a cuvette with an optical path length of $1 \mathrm{~cm}$. The relative standard deviation values were also calculated (Table 1). Low standard deviation values 


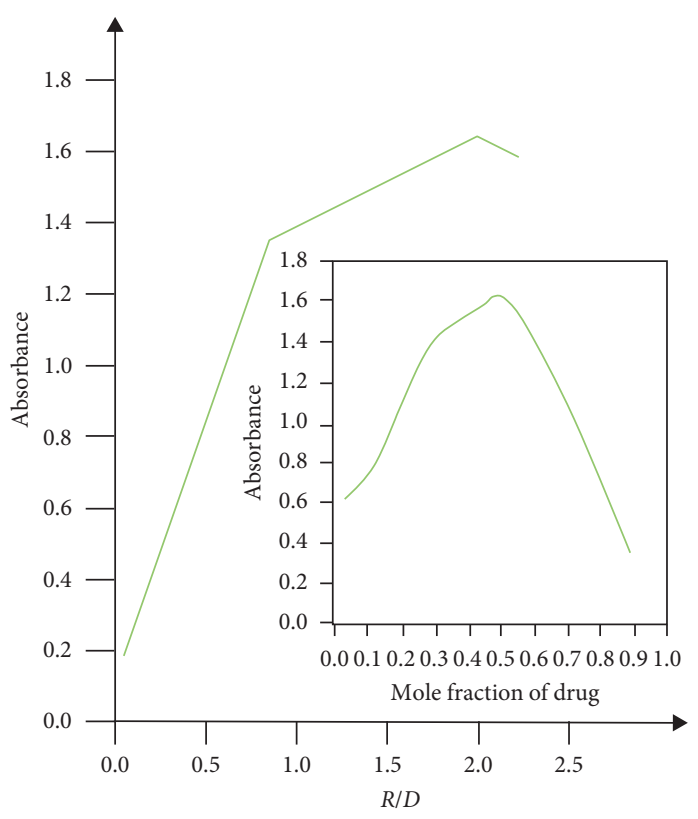

(a)

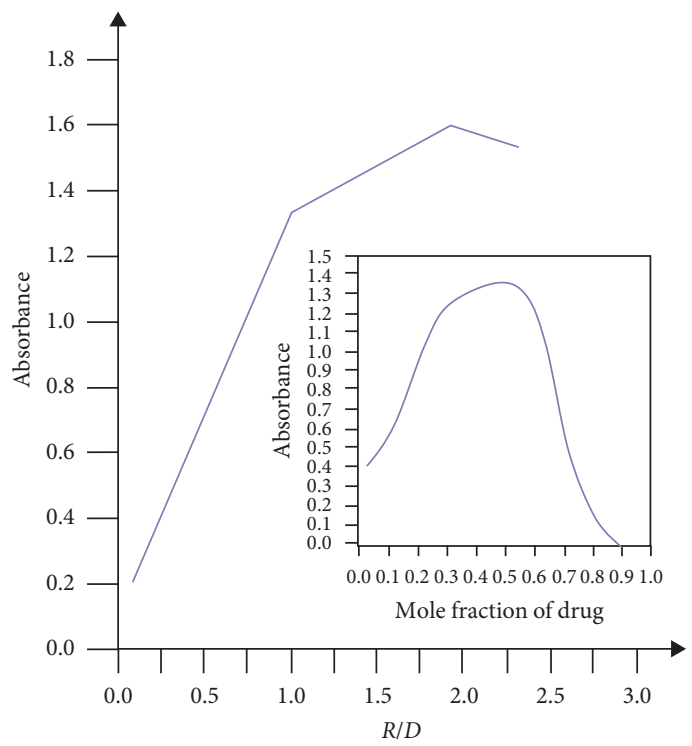

(c)

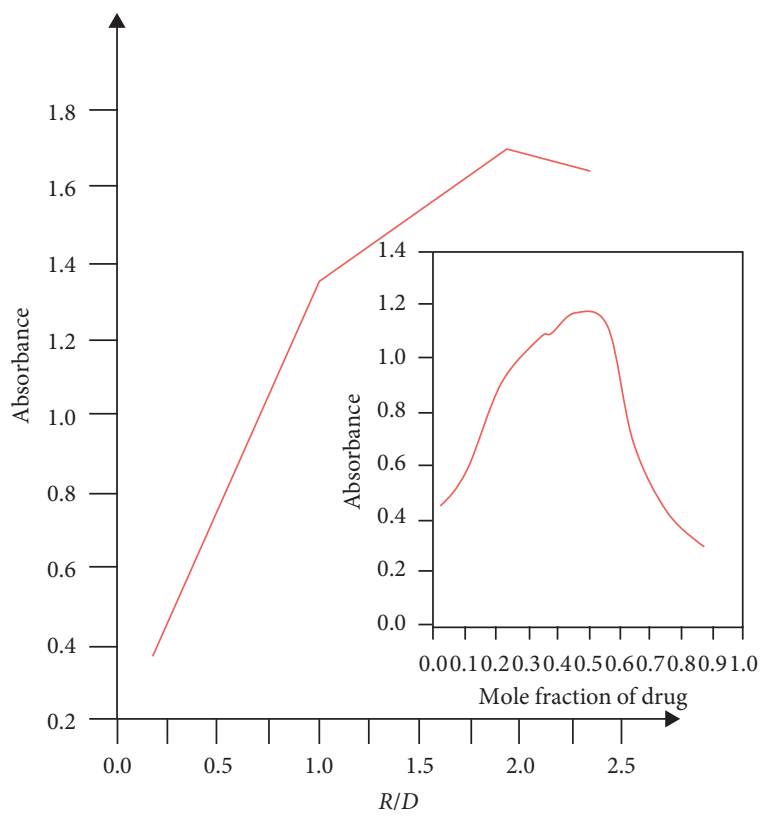

(b)

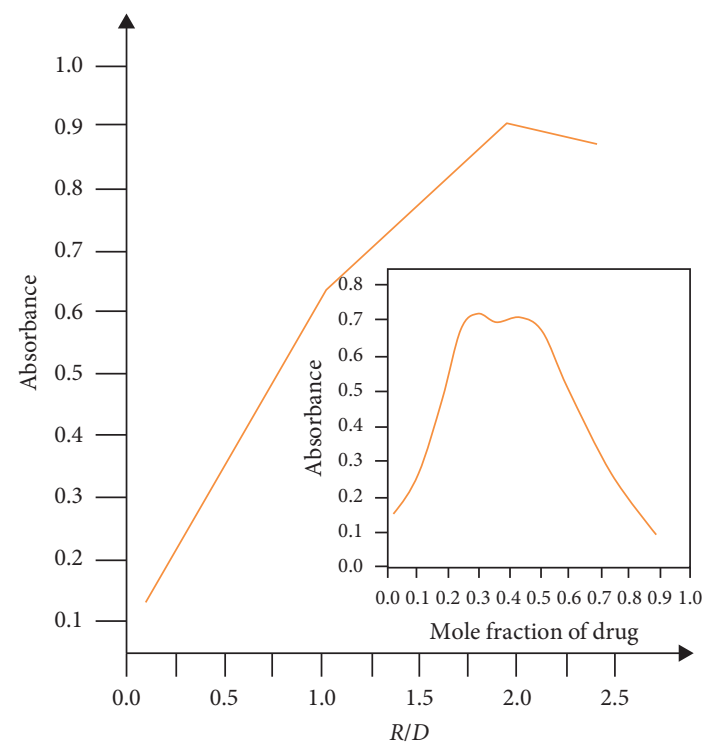

(d)

FIGURE 2: Stoichiometry of formed complexes between diaveridine and reagents V (a), VI (b), VII (c), and VIII (d) complexes by MRM and CVM method.

indicate that the proposed methods are accurate and precise, and thus they can be used easily for routine work in drug control laboratories.

Sensitivity of the methods can be determined through the calculation of Sandell sensitivity (SS) [21], which represents the number of micrograms of the analyte per $\mathrm{mL}$ of a solution having an absorbance of 0.001 for a path length of $1 \mathrm{~cm}$. The sensitivity is expressed in $\mu \mathrm{g} / \mathrm{cm}^{2}$ :

$$
\mathrm{SS}=\frac{1}{a \times 1000},
$$

where $a$ is the specific absorptivity.

The low Sandell sensitivity (SS) values (Table 1) indicate the high sensitivity of the proposed methods.
The detection limit (DL) for the proposed methods was calculated (Table 1) using the following equation [22]:

$$
\mathrm{DL}=3 s / k,
$$

where $s$ is the standard deviation of replicate determination values under the same conditions as for the sample analysis in the absence of the analyte and $(k)$ is the specific absorptivity (the slope of the calibration graph).

The results showed that in determination of diaveridine using IV reagent gives the smallest limit of detection $(0.62 \mu \mathrm{g} / \mathrm{mL})$.

The quantification limit QL can be calculated by the following equation [22]: 


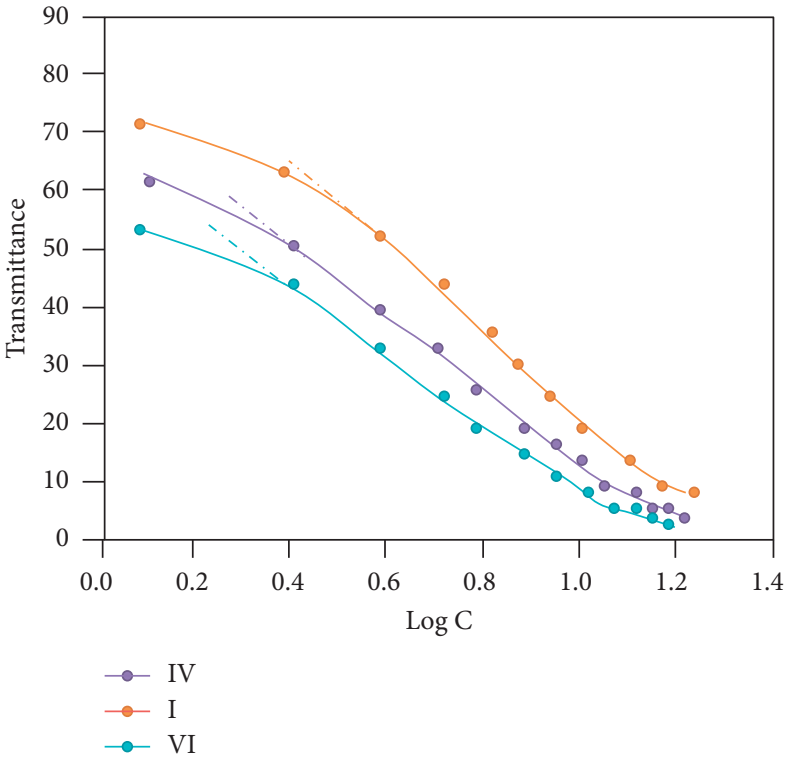

(a)

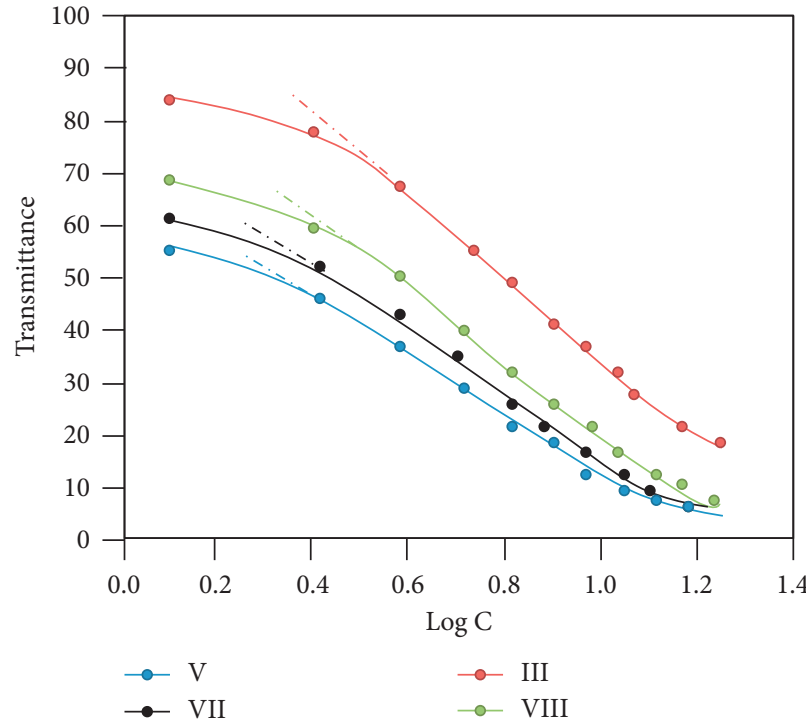

(b)

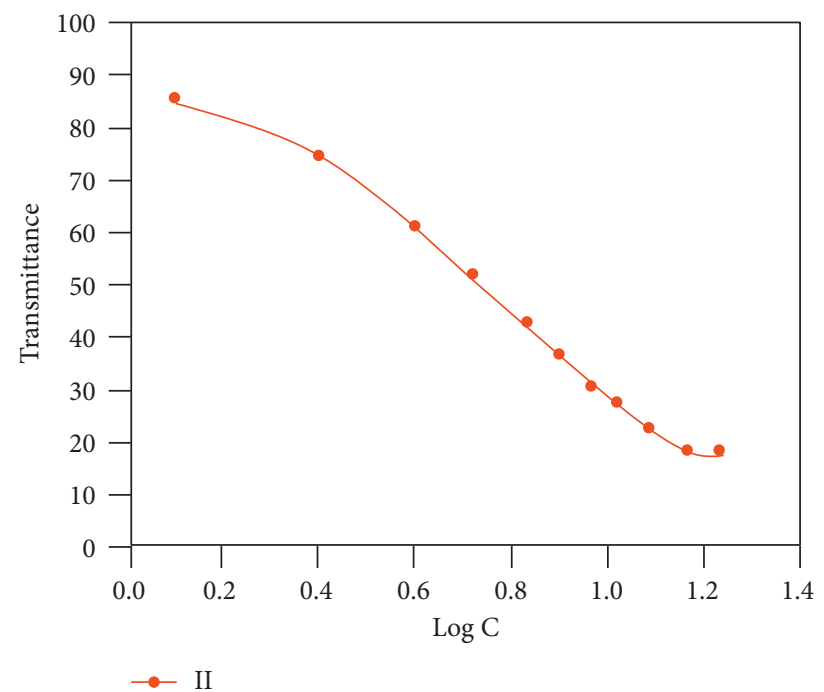

(c)

Figure 3: Ringbom plot for determination of diaveridine.

$$
\mathrm{QL}=10 s / k \text {. }
$$

The value of QL for reagent IV is $2.07 \mu \mathrm{g} / \mathrm{mL}$. So, it is the best reagent for the determination of diaveridine (Table 1).

Percentage relative standard deviation (RSD\%) as precision and percentage relative error ( $\mathrm{RE} \%$ ) as accuracy of the suggested method were calculated (Table 1). Precision was carried out by five determinations at different concentrations in these spectrophotometric methods. The percentage relative error was calculated using the following equation [23]:

$$
\mathrm{RE} \%=[(\text { real value }- \text { found value }) / \text { real value }] \times 100 \text {. }
$$

Using reagent III gives the smallest relative error $(0.1 \%)$ in the determination of the drug under investigation.
Also, ruggedness was tested by applying the proposed methods to the assay using the same operational conditions but using two different instruments at two different laboratories and different elapsed times. Results obtained from lab-to-lab and day-to-day variations were reproducible, as the relative standard deviations did not exceed 1\% (Table 2). The repeatability of the methods was also evaluated by performing four repeated measurements for using reagents under the optimum conditions, the low values of the standard deviation (Table 2), indicating that the methods are accurate and precise.

3.3. The Stability Constants of the Ion-Associate Complexes. The conditional stability constants $\left(K_{\mathrm{f}}\right)$ of the ion-associate complexes for the studied drug were calculated from the 
TABLE 2: The ruggedness and the repeatability data of the method.

\begin{tabular}{|c|c|c|c|c|c|c|c|c|}
\hline \multirow{2}{*}{ Reagent } & \multicolumn{4}{|c|}{ Interday } & \multicolumn{4}{|c|}{ Interlab } \\
\hline & Taken conc. $(\mu \mathrm{g} / \mathrm{mL})$ & Found conc. $(\mu \mathrm{g} / \mathrm{mL})$ & SD & RSD (\%) & Taken conc. $(\mu \mathrm{g} / \mathrm{mL})$ & Found conc. $(\mu \mathrm{g} / \mathrm{mL})$ & SD & RSD (\%) \\
\hline I & 9.10 & 8.97 & 0.016 & 0.18 & 9.10 & 9.13 & 0.021 & 0.23 \\
\hline II & 9.10 & 9.07 & 0.024 & 0.26 & 9.10 & 9.16 & 0.030 & 0.33 \\
\hline III & 9.10 & 9.00 & 0.032 & 0.36 & 9.10 & 9.05 & 0.033 & 0.37 \\
\hline IV & 9.10 & 8.97 & 0.053 & 0.59 & 9.10 & 9.08 & 0.026 & 0.29 \\
\hline $\mathrm{V}$ & 9.10 & 9.20 & 0.034 & 0.37 & 9.10 & 9.09 & 0.022 & 0.24 \\
\hline VI & 9.10 & 9.06 & 0.028 & 0.31 & 9.10 & 9.00 & 0.035 & 0.39 \\
\hline VII & 9.10 & 9.05 & 0.021 & 0.23 & 9.10 & 9.06 & 0.025 & 0.28 \\
\hline VIII & 9.10 & 9.08 & 0.041 & 0.45 & 9.10 & 9.07 & 0.026 & 0.29 \\
\hline
\end{tabular}

molar ratio data using the Harvey and Manning equation [24]. The formed complexes are fairly stable as indicated by the high values of the overall stability constants (Table 3 ).

The standard free energy change of complexation $\left(\Delta \mathrm{G}^{\circ}\right)$ (Table 3) was calculated by the following equation [25]:

$$
\Delta \mathrm{G}^{\circ}=-2.303 \mathrm{RT} \log K_{\mathrm{f}},
$$

where $\left(\Delta G^{\circ}\right)$ is the standard free energy change of the complex $\left(\mathrm{kJ} \cdot \mathrm{mol}^{-1}\right), R$ is the gas constant $\left(1.987 \mathrm{cal} \cdot \mathrm{mol}^{-1} \cdot \mathrm{C}^{-1}\right), T$ is the temperature in Kelvin, and $K_{\mathrm{f}}$ is the association constant of ion-associate complexes $\left(\mathrm{L} \cdot \mathrm{mol}^{-1}\right)$.

Generally, standard free energy changes become more negative as the association constants for molecular complex increase, because the bond between the components becomes stronger and thus the components are subjected to more physical strain or loss of freedom, so the values of $\Delta G^{\circ}$ more negative. In addition, negative values of standard free energy change indicate that the reactions are spontaneous.

\section{Applications of the Methods}

4.1. Spectrophotometric Determination of Diaveridine in Pure Preparation. The use of the method for the analysis of diaveridine in its pure state was examined by analyzing the samples using the proposed procedures. The results obtained are given in Table 4. The precision and accuracy of the methods were tested by analyzing five replicates of the drug within Beer's law ranges. The low values of standard deviation indicate good precision and reproducibility of the methods.

4.2. Spectrophotometric Determination of Diaveridine in Pharmaceutical Preparation. The use of the proposed method was tested also by determination of the drug under the study in dosage form manufactured in the local companies in the Egyptian markets such as New-Cox powerful anticoccidial water-soluble powder which was obtained from (Atco pharma for pharmaceutical Industry, Cairo, Egypt). The concentration of the drug in the dosage form was calculated from the appropriate calibration graphs.

The reagents which were selected to study the analytical applications of the methods are I to $\mathrm{V}$ due to their high molar absorptivity. There was no shift in the absorption maximum due to the presence of other constituents of the dosage form (Table 5).

The results of the proposed methods for determination of diaveridine were compared with those obtained by the reference method taken from British pharmacopeia [26] (aqueous titration method using $0.1 \mathrm{~mol} / \mathrm{L}$ perchloric acid as titrant in presence of violet crystal solution as an indicator). The results revealed that no significant differences between the performance of the proposed methods and the official or reference methods regarding to accuracy and precision, so the developed methods may be recommended for routine and quality control analysis of the investigated drug.

4.3. Statistical Treatment of the Data of the Determination of Diaveridine in Pure and Pharmaceutical Forms. The $t$-test [27] was applied to investigate the agreement between mean values obtained from the determination of the studied drug in pure and pharmaceutical forms. The F-test [27] indicates whether there is a difference between two methods according to their standard deviations. The performance of the proposed methods was assessed by calculation of the $t$ and $F$-values compared with the reference methods which were developed by the British Pharmacopeia. The calculated $t$-values and $F$-values at $95 \%$ confidence limits and four degrees of freedom for the determination of the studied drug in its pure and pharmaceutical preparation are presented in Tables 4 and 5 .

\section{Conclusion}

The ion-associate complexes of diaveridine using eight sulfonphthalein dyes were prepared in a solution and studied spectrophotometrically. The proposed methods are simple, quick, and economic and provide sensitive procedures compared with other reported spectrophotometric methods. The stoichiometric ratio of the reaction products of drugs with reagents is $1: 1$ and $1: 2$ (drug:reagent). The results showed that the III reagent gave the highest molar absorptivity value $\left(2.89 \times 10^{4} \mathrm{~L} \cdot \mathrm{mol}^{-1} \cdot \mathrm{cm}^{-1}\right)$ because the sensitivity and the stability of absorbance of ion-associate system including electron attracting group were better than other systems including the electron donating group. The methods were validated in terms of linearity, sensitivity, 
TABle 3: Association constant and free energy $\left(\Delta \mathrm{G}^{\circ}\right)$ obtained from the molar ratio and continuous variation method of ion-associate complexes under investigation.

\begin{tabular}{lcccc}
\hline Ion pair & & $\log K_{\mathrm{f}}$ & & $\Delta \mathrm{G}^{\circ}\left(\mathrm{Kcal}^{\prime}\right)$ \\
& $\log K_{\mathrm{f} 1}(1: 1)$ & $\log K_{\mathrm{f} 2}(1: 2)$ & $\Delta \mathrm{G}_{1}^{\circ}(1: 1)$ & $\Delta \mathrm{G}_{2}^{\circ}(1: 2)$ \\
\hline D-I & 4.72 & 10.74 & -6.4365 & -14.64580 \\
D-II & 4.89 & 10.91 & -6.6683 & -14.87750 \\
D-III & 4.60 & 10.62 & -6.2729 & -14.48213 \\
D-IV & 4.70 & 10.71 & -6.4098 & -14.60004 \\
D-V & 4.72 & 10.81 & -6.4371 & -14.7410 \\
D-VI & 4.63 & 10.66 & -6.3137 & -14.53670 \\
D-VII & 4.62 & 10.61 & -6.3001 & -14.46850 \\
D-VIII & 4.54 & 9.95 & -6.1912 & -13.56847 \\
\hline
\end{tabular}

TABLE 4: Determination of diaveridine in pure preparation.

\begin{tabular}{|c|c|c|c|c|c|c|}
\hline Reagent & Taken conc. $(\mu \mathrm{g} / \mathrm{mL})$ & Found conc. ${ }^{\mathrm{a}}(\mu \mathrm{g} / \mathrm{mL})$ & Mean recovery $(\%)$ & SD & $F^{\mathrm{b}}$-test & $t^{\mathrm{b}}$-test \\
\hline \multirow{2}{*}{ I } & 9.1 & 9.07 & 99.7 & 0.035 & 0.494 & 0.36 \\
\hline & 10.4 & 10.37 & 99.7 & 0.019 & 0.15 & 0.49 \\
\hline \multirow{2}{*}{ II } & 9.1 & 9.14 & 100.4 & 0.029 & 0.34 & 0.53 \\
\hline & 10.4 & 10.44 & 100.4 & 0.022 & 0.20 & 0.60 \\
\hline \multirow{2}{*}{ III } & 9.1 & 9.15 & 100.5 & 0.034 & 0.46 & 0.61 \\
\hline & 10.4 & 10.43 & 100.3 & 0.020 & 0.13 & 0.50 \\
\hline \multirow{2}{*}{ IV } & 9.1 & 9.15 & 100.6 & 0.027 & 0.29 & 0.68 \\
\hline & 10.4 & 10.43 & 100.3 & 0.047 & 0.88 & 0.31 \\
\hline \multirow{2}{*}{$\mathrm{V}$} & 9.1 & 9.15 & 100.6 & 0.039 & 0.61 & 0.57 \\
\hline & 10.4 & 10.46 & 100.6 & 0.057 & 1.25 & 0.57 \\
\hline \multirow{2}{*}{ VI } & 9.1 & 9.13 & 100.3 & 0.039 & 0.61 & 0.34 \\
\hline & 10.4 & 10.42 & 100.2 & 0.067 & 1.80 & 0.17 \\
\hline \multirow{2}{*}{ VII } & 9.1 & 9.05 & 99.5 & 0.034 & 0.46 & 0.55 \\
\hline & 10.4 & 10.33 & 99.3 & 0.046 & 0.85 & 0.73 \\
\hline \multirow{2}{*}{ VIII } & 9.1 & 9.13 & 100.3 & 0.042 & 0.71 & 0.33 \\
\hline & 10.4 & 10.45 & 100.5 & 0.033 & 0.44 & 0.62 \\
\hline
\end{tabular}

${ }^{a}$ Found concentration is the average of five values. ${ }^{b}$ Theoretical values for $t$ - and $F$-test at five degrees of freedom and $95 \%$ confidence limits are 2.57 and 5.05 , respectively.

Table 5: Determination of diaveridine in pharmaceutical preparation (New-Cox).

\begin{tabular}{|c|c|c|c|c|c|c|}
\hline Reagent & Taken conc. $(\mu \mathrm{g} / \mathrm{mL})$ & Found conc. $^{\mathrm{a}}(\mu \mathrm{g} / \mathrm{mL})$ & Mean recovery $(\%)$ & SD & $F^{\mathrm{b}}$-test & $t^{\mathrm{b}}$-test \\
\hline \multirow{2}{*}{ I } & 7.80 & 7.92 & 101.5 & 0.024 & 0.23 & 3.18 \\
\hline & 11.7 & 11.82 & 101.3 & 0.029 & 0.34 & 1.57 \\
\hline \multirow{2}{*}{ II } & 7.80 & 8.08 & 103.6 & 0.026 & 0.27 & 3.90 \\
\hline & 11.7 & 11.90 & 101.8 & 0.042 & 0.71 & 2.19 \\
\hline \multirow{2}{*}{ III } & 7.80 & 7.99 & 102.4 & 0.039 & 0.61 & 2.15 \\
\hline & 11.7 & 11.90 & 101.8 & 0.068 & 1.85 & 1.71 \\
\hline \multirow{2}{*}{ IV } & 7.80 & 7.98 & 102.3 & 0.065 & 1.69 & 1.58 \\
\hline & 11.7 & 11.86 & 101.4 & 0.032 & 0.41 & 2.01 \\
\hline \multirow{2}{*}{$\mathrm{V}$} & 7.80 & 7.96 & 102.1 & 0.026 & 0.27 & 2.22 \\
\hline & 11.7 & 11.85 & 101.3 & 0.050 & 1.01 & 1.50 \\
\hline
\end{tabular}

${ }^{\mathrm{a}}$ Found concentration is the average of five values. ${ }^{\mathrm{b}}$ Theoretical values for $t$ - and $F$-test at five degrees of freedom and $95 \%$ confidence limits are 2.57 and 5.05 , respectively.

detection and qualification limits, accuracy, precision, ruggedness, and repeatability. Finally, the spectrophotometric determination of diaveridine in pure and pharmaceutical forms was performed. The obtained results showed that there is no shift in the absorption maximum due to the presence of other constituents of the dosage form. The present methods are in good agreement with the official methods. 


\section{Data Availability}

The data used to support the findings of this study are available from the corresponding author upon request.

\section{Conflicts of Interest}

The authors declare that they have no conflicts of interest.

\section{References}

[1] P. G. Hatman, "Molecular aspects and mechanism of action of dihydrofolate reductase inhibitor," Journal of Chemotherapy, vol. 5 , p. 369, 1993.

[2] T. Ono, T. Sekiya, Y. Takahashi, F. Sasaki, F. Izumiyama, and E. Nishidate, "The genotoxicity of diaveridine and trimethoprim," Environmental Toxicology and Pharmacology, vol. 3, no. 4, pp. 297-306, 1997.

[3] B. Shao, J. Zhang, and H. Duan, "Development of a rapid LC-MS-MS method for multi-class determination of 14 coccidiostat residues in eggs and chicken," Chromotographia, vol. 69, no. 9-10, pp. 1083-1088, 2009.

[4] A. Numan, B. Musial, and N. D. Danielson, "Spectrophotometric determination of diaminopyrimidines using benzoquinone," Journal of Pharmaceutical and Biomedical Analysis, vol. 30, no. 3, pp. 761-771, 2002.

[5] S. S. Tseng and T. U. Smith, "A microtiter plate assay for sulfonamides," Analytical Letters, vol. 27, no. 8, pp. 15071515, 1994.

[6] R. A. Mellado, B. Gomes, and C. Martinez, "Continuous-flow spectrophotometric determination of sulfadiazine by diazotisation with in situ preparation of nitrite," Analytica Chimica Acta, vol. 308, no. 1-3, pp. 451-456, 1995.

[7] H. Wang, B. Yuan, Z. Zeng et al., "Identification and elucidation of the structure of in vivo metabolites of diaveridine in chicken," Journal of Chromatography B, vol. 965, pp. 91-99, 2014.

[8] M. A. Brooks, J. A. De Silva, and L. D'Aroconte, "Determination of trimethoprim and its $\mathrm{N}$-oxide metabolites in urine of man, dog, and rat by differential pulse polarography," Journal of Pharmaceutical Sciences, vol. 62, no. 8, pp. 13951397, 1973.

[9] G. H. Jeffery, J. Bassett, J. Mendham, Denney, and R. C. Vogel's, Textbook of Quantitative Chemical Analysis, Longman Scientific and Technical, Harlow, UK, 5th edition, 1989.

[10] M. R. Keskar and R. M. Jugade, "Spectrophotometric determination of cefixime trihydrate in pharmaceutical formulations based on ion-pair reaction with bromophenol blue," Analytical Chemistry Insights, vol. 10, pp. 11-16, 2015.

[11] S. A. M. Abdulrahma and K. Basavaiah, "Spectrophotometric determination of dothiepin hydrochloride in pharmaceuticals through ion-pair complexation reaction," Chemical Industry and Chemical Engineering Quarterly, vol. 18, no. 2, pp. 339$347,2012$.

[12] S. G. Naira, J. V. Shaha, P. A. Shaha, M. Sanyalb, and P. S. Shrivastav, Eurasian Journal of Analytical Chemistry, vol. 10, no. 2, pp. 68-83, 2015.

[13] A. Alshabrawy, A. Mostafa, and N. Abotaleb, Journal of Advanced Pharmacy Research, vol. 1, no. 4, pp. 193-200, 2017.

[14] A. I. Vogel, Practical Organic Chemistry Including Quantitative Organic Analysis, Longman, London, UK, 3rd edition, 1956.
[15] N. Rahman and S. N. Azmi, "Extractive spectrophotometric methods for determination of diltiazem $\mathrm{HCl}$ in pharmaceutical formulations using bromothymol blue, bromophenol blue and bromocresol green," Journal of Pharmaceutical and Biomedical Analysis, vol. 24, no. 1, pp. 33-41, 2000.

[16] P. Job, "Formation and stability of inorganic complexes in solution," Annali di Chimica Applicata, vol. 9, pp. 113-203, 1982.

[17] J. H. Yoe and A. L. Jones, "Colorimetric Determination of Iron with Disodium-1,2-dihydroxybenzene-3,5-disulfonate," Industrial \& Engineering Chemistry Analytical Edition, vol. 6, p. 111, 1944.

[18] A. Ringbom, "Über die Genauigkeit der colorimetrischen Analysenmethoden I," Zeitschrift für Analytische Chemie, vol. 115, pp. 332-343, 1939.

[19] A. D. Peter Edwardson, G. Bhaskar, and E. J. Fairbrother, "Method validation in pharmaceutical analysis," Journal of Pharmaceutical and Biomedical Analysis, vol. 8, no. 8-12, pp. 929-933, 1990.

[20] G. H. Ayers and B. D. Narang, "Spectrophotometric determination of palladium(II) with 5 (p-dimethylaminobenzylidene)rhodanine," Analytica Chimica Acta, vol. 24, pp. 241-249, 1961.

[21] E. B. Sandell, Colorimetric Determination of Traces Metals, Interscience, New York, NY, USA, 3rd edition, 1959.

[22] The European Agency for the Evaluation of Medical Products, ICH Topics Q2B Note for Guidance on Validation of Analytical procedures, Methodology CPMP/ICH/281/95, 1996.

[23] A. Amin, A. Gouda, R. El-Shaikh, and F. Zahran, "Spectrophotometric determination of gatifloxacin in pure form and in pharmaceutical formulation," Spectrochimica Acta Part A: Molecular and Biomolecular Spectroscopy, vol. 67, no. 5, pp. 1306-1312, 2007.

[24] A. E. Harvey and D. L. Manning, "Spectrophotometric methods of establishing empirical formulas of colored complexes in solution," Journal of the American Chemical Society, vol. 72, pp. 4488-4493, 1950.

[25] A. N. Martin, J. Swarbrick, and A. Cammarata, Physical Pharmacy, Lee and Febiger, Philadelphia, PA, USA, 3rd edition, 1969.

[26] British Pharmacopoia, London, Statistics in Analytical Chemistry, Chapter 3, J. C. Miller and J. N. Miller, Eds., Ellis Horwood, Chichester, UK, 3rd edition, 1993.

[27] J. S. Fritz and G. H. Schenk, Quantitative Analytical Chemistry, Allyn and Bacon, Inc, Boston, MA, USA, 4th edition, 1979. 

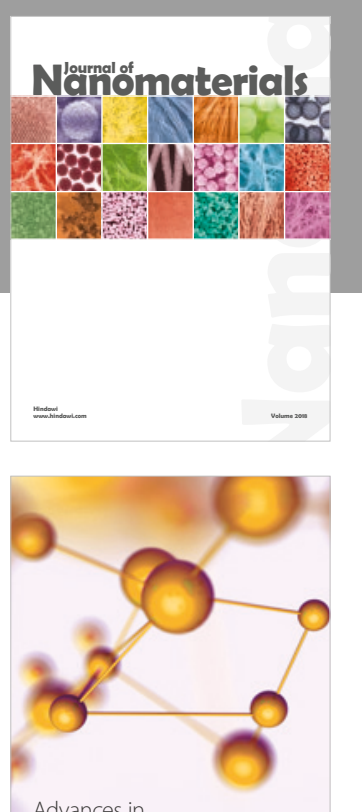

Physical Chemistry
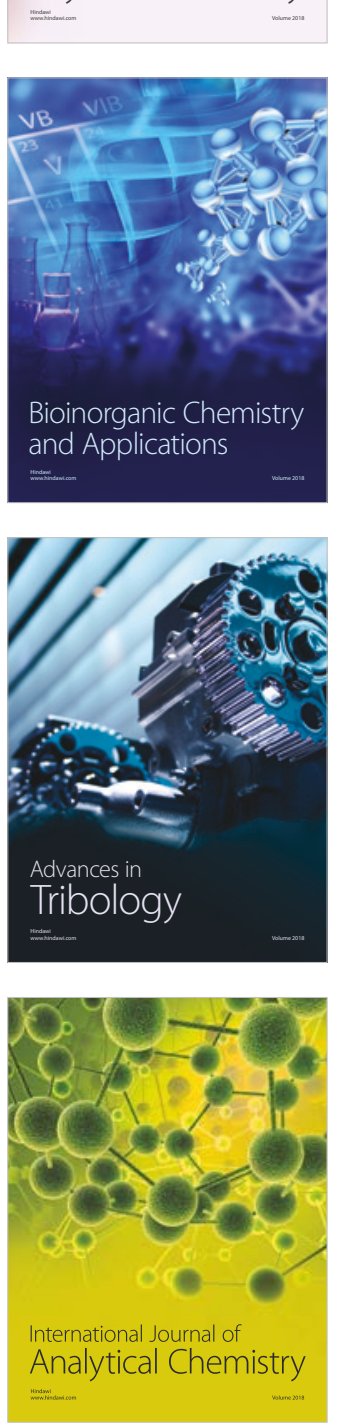

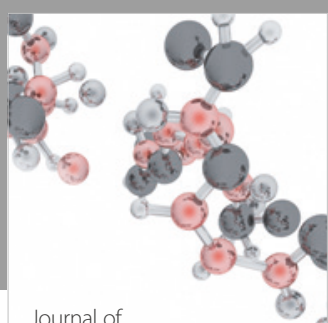

Analytical Methods

in Chemistry

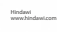

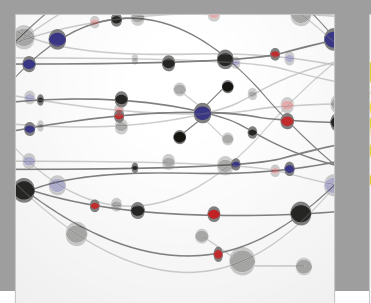

The Scientific World Journal

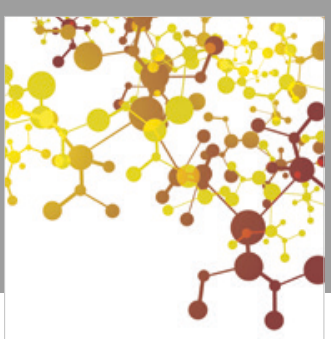

Journal of

Applied Chemistry
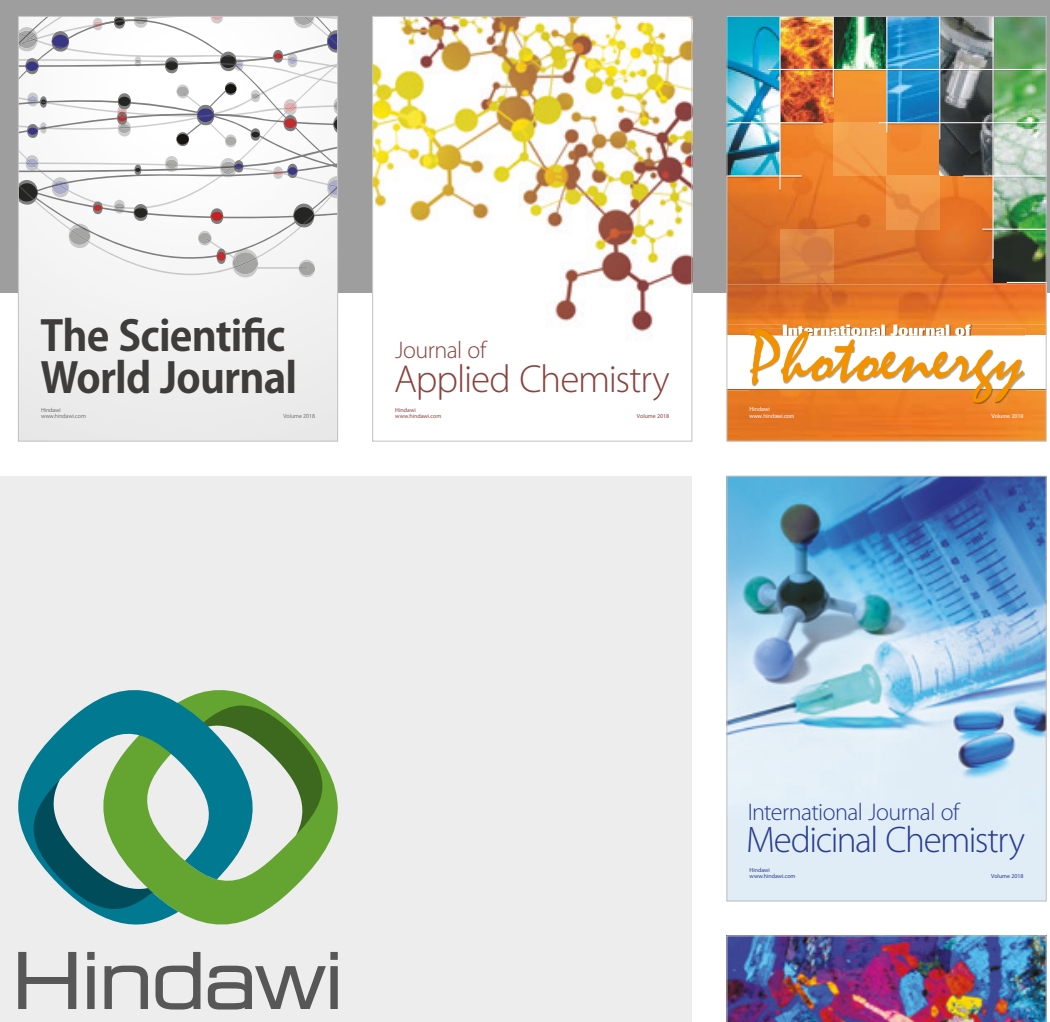

Submit your manuscripts at

www.hindawi.com
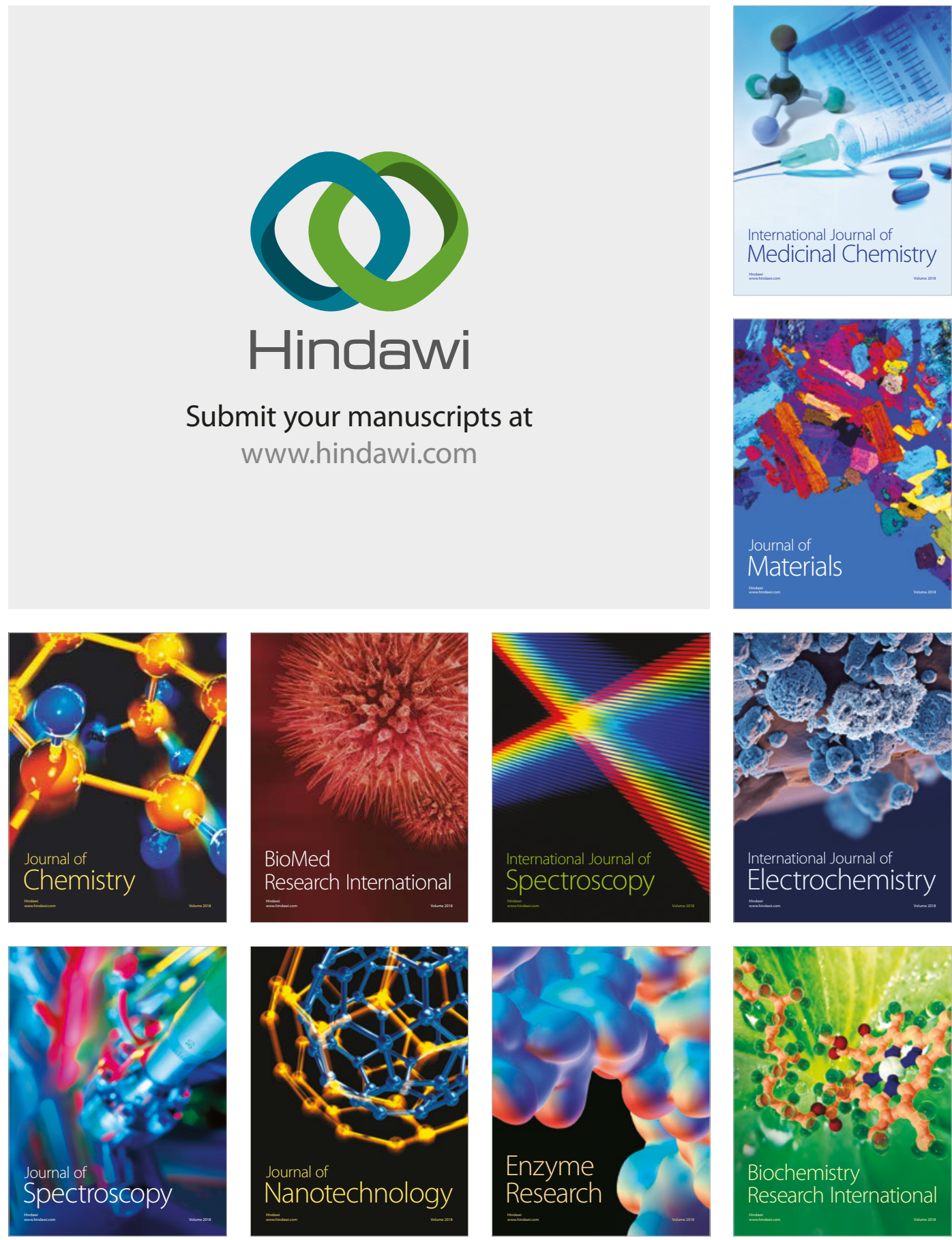
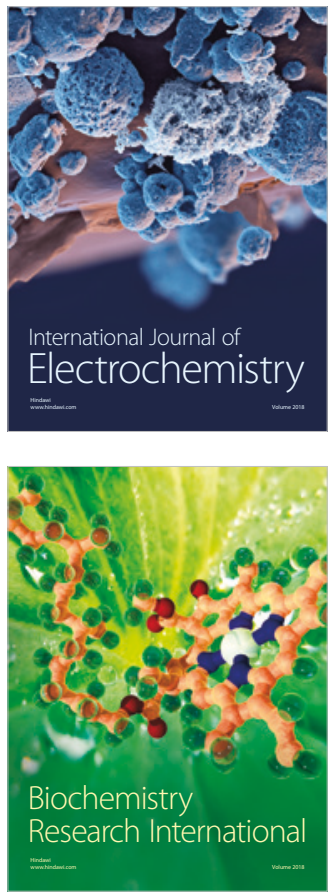